Cite this: RSC Advances, 2013, 3, 7277

\title{
A novel antimicrobial agent reduces oxidative stress in cells $†$
}

Received 6th February 2013,

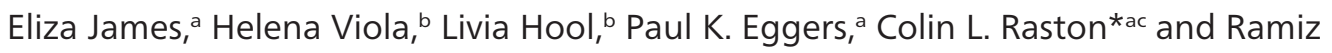

Accepted 21st March 2013

A. Boulos*ac

DOI: $10.1039 / \mathrm{c} 3 \mathrm{ra40658j}$

www.rsc.org/advances

1,3,5-Tris[(1E)-2'-(4' '-benzoic acid)vinyl]benzene] (Ramizol $\left.{ }^{\mathrm{TM}}\right)$ is a potent and non-toxic synthetic antimicrobial agent, and we now establish that it is also a potent inhibitor of reactive oxygen species (ROS) generation, with similar antioxidant activity to $\alpha$-tocopherol (Vitamin E), which is a standard antioxidant drug. The results show that Ramizol ${ }^{\mathrm{TM}}$ decreases ROS to basal levels in PC12 cells and mouse and guinea pig myocytes, and demonstrate its protective nature from oxidative damage to the cells. The continuing challenge to discover antibiotics with no or few side effects makes Ramizol ${ }^{\mathrm{TM}}$ a very attractive candidate for the potential treatment of infections.

\section{Introduction}

An antioxidant is a molecule capable of slowing or preventing the oxidation of other molecules via the transfer of electrons. In general, oxidation reactions can produce free radicals which start chain reactions that damage cells. Antioxidants terminate such reactions by removing free radical intermediates and inhibit other oxidation reactions by being oxidized themselves. ${ }^{1}$ Oxidative stress may induce cell damage, ultimately leading to cell death by apoptosis or necrosis. An increasing number of studies show that antioxidants can block cell death and may have therapeutic properties in animal models of diseases such as Alzheimer's, Parkinson's, hypertension, atherosclerosis, stroke, diabetes, cancer and inflammatory disorders. ${ }^{2,3}$ Therefore, in modern Western medicine, the balance between antioxidation and oxidation is believed to be critical for maintaining a healthy biology, ${ }^{4,5}$ and the status of protective mechanisms against oxidants is important. The antioxidants in humans reflect the dynamic balance between antioxidant defence and prooxidant conditions and they have

${ }^{a}$ Centre for Strategic Nano-Fabrication, School of Chemistry and Biochemistry, The University of Western Australia, Crawley, WA 6009, Australia.

E-mail: ramiz.boulos@uwa.edu.au; Tel: 61864884422

${ }^{b}$ School of Anatomy, Physiology and Human Biology, The University of Western Australia M311, 35 Stirling Highway, Crawley, WA 6009, Australia

${ }^{c}$ School of Chemical and Physical Sciences, Flinders University, Bedford Park, SA 5042, Australia.E-mail: colin.raston@flinders.edu.au

† Electronic supplementary information (ESI) available. See DOI: 10.1039/c3ra40658j been suggested as a useful tool in estimating the risk of oxidative damage. $^{6-8}$

The symmetrical molecule 1,3,5-tris[(1E)-2'-(4'-benzoic acid)vinyl]benzene] (Ramizol ${ }^{\mathrm{TM}}$ ) (Fig. 1) has recently been established as a potent antimicrobial molecule with a minimum inhibitory concentration (MIC) against MRSA of $2 \mu \mathrm{g} \mathrm{ml}{ }^{-1} \cdot{ }^{9}$ Ramizol $^{\mathrm{TM}}$ shows no cytotoxicity in L929 cells (up to $500 \mu \mathrm{g} \mathrm{ml}^{-1}$ ) and no haemolytic activity in sheep erythrocytes up to $50 \mu \mathrm{g} \mathrm{ml}{ }^{-1}$, at 25 times the MIC of MRSA. Moreover the AMES test establishes that there is no mutagenic activity due to Ramizol ${ }^{\mathrm{TM}}$ against the test organism S. typhimurium for concentrations up to $300 \mu \mathrm{g} \mathrm{ml}{ }^{-1}$. Its design as an antimicrobial compound was based on molecular docking experiments with the mechanosensitive channel of large conductance (MscL) protein. ${ }^{10}$ In the present study we investigate the antioxidant properties of $\mathrm{Ramizol}^{\mathrm{TM}}$ in different oxidative stress conditions in PC12 cells and mouse and guinea pig myocytes and discuss the scope for further strategic development of new therapies.

\section{Materials and methods}

\section{Reagents}

The reagents 1,3,5-tribromobenzene, $\quad \mathrm{Pd}_{2}(\mathrm{dba})_{3} \cdot \mathrm{CHCl}_{3}$, $t$ - $\mathrm{Bu}_{3} \mathrm{PHBF}_{4}, \mathrm{Cy}_{2} \mathrm{NMe}$ and ethyl 4-vinylbenzoate (for the synthesis of Ramizol ${ }^{\mathrm{TM}}$ ), poly-L-lysine, menadione, EDTA, glutamate and D-<smiles>O=C(O)c1ccc(/C=C/c2cc(/C=C/c3ccc(C(=O)O)cc3)cc(/C=C/c3ccc(C(=O)O)cc3)c2)cc1</smiles>

Fig. 1 Chemical structure of 1,3,5-Tris[(1E)-2'-(4'-benzoic acid)vinyl]benzene] (Ramizol ${ }^{\mathrm{TM}}$ ). 
$\alpha$-tocopherol succinate were purchased from Sigma Aldrich, Australia. RPMI1640 cell culture media, fetal calf serum, horse serum, MEM non-essential amino acids, penicillin, streptomycin, PBS, DPBS, Hanks' balanced salt solution (HBSS), trypsin, trypsinEDTA, sodium pyruvate, L-glutamine, cell dissociation buffer (enzyme free) and Live/Dead assay kit were purchased from Invitrogen Australia. The OxiSelect Intracellular ROS Assay Kit (Green Fluorescence) STA-342, was purchased from Cell Bio Labs., USA.

\section{Synthesis of Ramizol ${ }^{\mathrm{TM}}$}

The synthesis of Ramizol ${ }^{\mathrm{TM}}$ followed the literature procedure with minor changes. ${ }^{11}+$ Ethyl acetate $(20 \%)$ in hexane was used for monitoring the progress of the Heck cross coupling reaction between 1,3,5-tribromobenzene and ethyl 4-vinylbenzoate, using TLC and 20:80 ethyl acetate-dichloromethane for eluting the product. Purification of the final product from the saponification reaction involved column chromatography using a 20:80 methanol-tetrahydrofuran solvent system, followed by the addition of diethyl ether as an anti-solvent to wash the product.

\section{Cell culture and treatment}

Stock cultures of PC12 cells, ${ }^{12}$ purchased from ATCC, were grown routinely in $75 \mathrm{~cm}^{2}$ tissue culture flasks in RPMI 1640 supplemented with $10 \%(\mathrm{v} / \mathrm{v})$ heat-inactivated horse serum, and $5 \%(\mathrm{v} / \mathrm{v})$ heat-inactivated fetal calf serum, to which penicillin $(50 \mathrm{U}$ $\left.\mathrm{ml}^{1}\right)$ and streptomycin $\left(50 \mu \mathrm{g} \mathrm{ml}{ }^{-1}\right)$ were added. Cultures were maintained at $37{ }^{\circ} \mathrm{C}$ in a humidified incubator containing $95 \%$ air and $5 \% \mathrm{CO}_{2}$. The cells were passed twice a week. One day prior to experimentation, the PC12 cells were plated on poly-L-lysine $(10 \mu \mathrm{g}$ $\mathrm{mL}^{-1}$ ) coated at a density of 10000 cells per well in 96 well plates and $2 \times 10^{5}$ cells per well in 6 well plates. Ramizol ${ }^{\mathrm{TM}}$ was prepared in different concentrations $(3,1,0.3,0.1,0.01,0.01 \mathrm{mg}$ $\mathrm{mL}^{-1}$ ) using RPMI media and then the PC12 cells were treated with this preparation for $24 \mathrm{~h}$ for cytotoxicity tests. $\alpha$-Tocopherol (A-T) is the main vitamin E component used as a standard drug in ROS experiments.

\section{Cell viability test}

In order to assess the cytotoxic effect of Ramizol ${ }^{\mathrm{TM}}$ on PC12 cells, we investigated the viability of PC12 cells incubated with a series of concentrations of Ramizol ${ }^{\mathrm{TM}}$ from 3 to $0.001 \mathrm{mg} \mathrm{mL}^{-1}$ for $24 \mathrm{~h}$. After $24 \mathrm{~h}$ the Ramizol ${ }^{\mathrm{TM}}$ was removed and the cells were washed 3 times with PBS after which $1 \mu \mathrm{M}$ calcein-AM and $2 \mu \mathrm{M}$ Ethidium homodimer (Live and dead assay kit) were added and the cells then incubated at $37{ }^{\circ} \mathrm{C}$ in $5 \% \mathrm{CO}_{2}$ for $30 \mathrm{~min}$. Images were taken at 4 locations in each well for three replicates of each concentration using a Nikon Inverted Fluorescence microscope.

\section{Effect of Ramizol ${ }^{\mathrm{TM}}$ on intracellular reactive oxygen species (ROS) generation, in PC12 cells}

Intracellular accumulation of hydrogen peroxide was determined with DCFH-DA. This non-fluorescent compound accumulates within cells upon deacetylation. DCFH then reacts with the reactive oxygen species to form fluorescent dichlorofluorescein (DCF). PC12 cells were plated in 96-well black and clear bottom plates and grown for $24 \mathrm{~h}$ before the addition of 1X DCFH-DA, incubation for $60 \mathrm{~min}$ at $37{ }^{\circ} \mathrm{C}$, and then treatment with Ramizol $^{\mathrm{TM}}$ at $0.1 \mathrm{mg} \mathrm{mL}^{-1}, \mathrm{~A}-\mathrm{T}(10 \mu \mathrm{M})$ and stressors $1 \mathrm{mM}$ $\mathrm{H}_{2} \mathrm{O}_{2}, 500 \mu \mathrm{M}$ menadione and $100 \mathrm{mM}$ glutamate, respectively for $60 \mathrm{~min}$. Cells were then washed 3 times with Hank's balanced salt solution (HBSS without phenol red) at room temperature. Cellular fluorescence was measured using an Enspire multimode plate reader using an excitation wavelength of $480 \mathrm{~nm}$ and emission wavelength of $530 \mathrm{~nm}$ (Software version 4.1.) (Perkin Elmer, USA). Results were expressed as Relative Fluorescence Units (RFU).

\section{Effect of Ramizol ${ }^{\mathrm{TM}}$ on $\mathrm{H}_{2} \mathrm{O}_{2}$ induced increase in superoxide production in adult mouse and guinea pig cardiac myocytes}

Superoxide generation was assessed in individual intact adult mouse and guinea pig cardiac myocytes. Animals were anesthetised using an intraperitoneal injection of pentobarbitone sodium (240 $\mathrm{mg} \mathrm{kg}^{-1}$ ) prior to the excision of the heart as approved by The Animal Ethics Committee of The University of Western Australia, in accordance with the Australian Code of Practice for the Care and Use of Animals for Scientific Purposes (NH\&MRC, 7th Edition, 2004). Cells were isolated as previously described. ${ }^{13}$ Superoxide generation was assessed in the myocytes before and after transient exposure to $30 \mu \mathrm{mol} \mathrm{L}{ }^{-1} \mathrm{H}_{2} \mathrm{O}_{2}$ using the fluorescent indicator dihydroethidium (DHE, $5 \mu \mathrm{M}, 515-560 \mathrm{~nm}$ ex filter, 590 long pass em) at $37{ }^{\circ} \mathrm{C}$ as previously described. ${ }^{14}$ Transient exposure to 30 $\mu \mathrm{mol} \mathrm{L}{ }^{-1} \mathrm{H}_{2} \mathrm{O}_{2}$ was achieved through the extracellular application of $30 \mu \mathrm{mol} \mathrm{L}{ }^{-1} \mathrm{H}_{2} \mathrm{O}_{2}$ for $5 \mathrm{~min}$ followed by $10 \mu \mathrm{mol} \mathrm{mL}{ }^{-1}$ catalase to degrade the $\mathrm{H}_{2} \mathrm{O}_{2}$. The fluorescent signal was measured on a Hamamatsu Orca ER digital camera attached to an inverted Nikon TE2000-U microscope. Fluorescent images were taken at $1 \mathrm{~min}$ intervals with $200 \mathrm{~ms}$ exposure. Metamorph 6.3 was used to quantify the signal by manually tracing individual myocytes. An equivalent region not containing cells was used as background and was subtracted. Fluorescence was reported as a ratio of the slope of the signal measured at 16-30 min (treatment) over 1-15 min (basal). Basal fluorescence was assigned a value of 1.0.

\section{Statistical analysis}

Data were expressed as means \pm SEM of triplicate determinations from the independent experiments. The statistical significance of the data was assessed by standard analysis of variance (ANOVA) techniques followed by a Bonferroni test using Stat view version 5.0.1 software and $p$ values $\leqslant 0.05$ were considered statistically significant.

\section{Results}

\section{Cell viability test}

To assess the cytotoxic effect of Ramizol ${ }^{\mathrm{TM}}$, PC12 cells were treated with $\mathrm{Ramizol}^{\mathrm{TM}}$ at different concentrations ranging from 0.001 to $3 \mathrm{mg} \mathrm{mL}{ }^{-1}$ for $24 \mathrm{~h}$, Fig. 2. The control group received only RPMI media and was analyzed using a live and dead assay kit. Fig. 3 represents the cell viability test for Ramizol ${ }^{\mathrm{TM}}$. The concentration at which the cell viability reduced by approximately $50 \%\left(\mathrm{IC}_{50}\right.$ value) was established at $3 \mathrm{mg} \mathrm{mL} \mathrm{mL}^{-1}(47.38 \pm 6.2 \%)$ and the concentration used for the treatment of cells for all assays was found to be safer and protective, having $97.16 \pm 2.3 \%$ viable cells. 


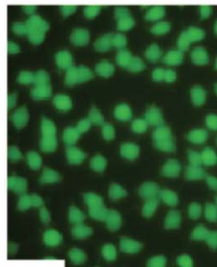

(a)

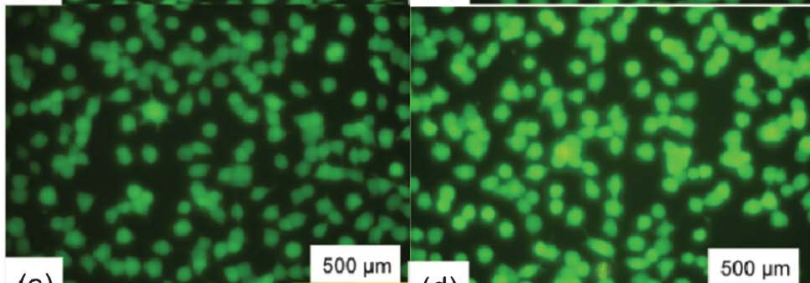

(c)

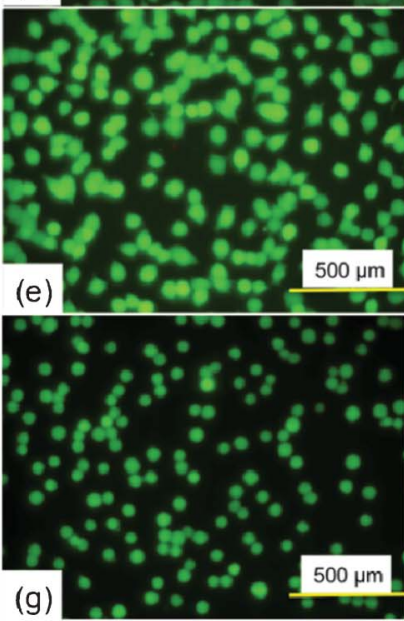

(d)

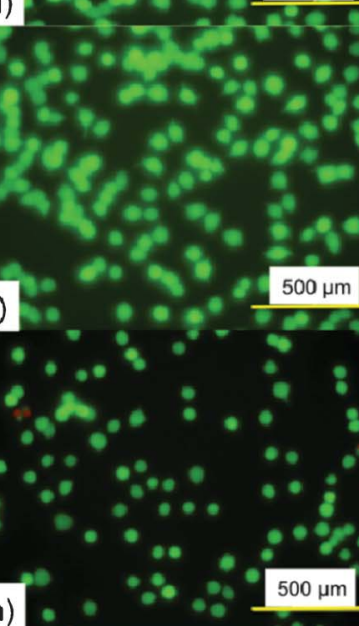

Fig. 2 Fluorescence images of PC12 cells in the presence of varying concentrations of Ramizol TM. (a) and (b) $0 \mathrm{mg} \mathrm{mL}^{-1}$, (c) $0.001 \mathrm{mg} \mathrm{mL}^{-1}$ (d) $0.01 \mathrm{mg} \mathrm{mL}^{-1}$ (e) 0.1 $\mathrm{mg} \mathrm{mL}^{-1}$ (f) $0.3 \mathrm{mg} \mathrm{mL}^{-1}$ (g) $1 \mathrm{mg} \mathrm{mL}^{-1}$ and (h) $3 \mathrm{mg} \mathrm{mL}^{-1}$.

Effect of Ramizol ${ }^{\mathrm{TM}}$ on intracellular ROS generation, in PC12 cells

The intracellular production of ROS was measured using a fluorescent probe, DCFDA, via a multimode plate reader. ROS production increased 10 fold after treatment with $\mathrm{H}_{2} \mathrm{O}_{2}$, menadione and glutamate treatment, Fig. 4 , which was significantly ( $p$ $\leqslant 0.05)$ different from the no treatment group. The group pretreated with Ramizol ${ }^{\mathrm{TM}}$ showed a two-fold increase in ROS

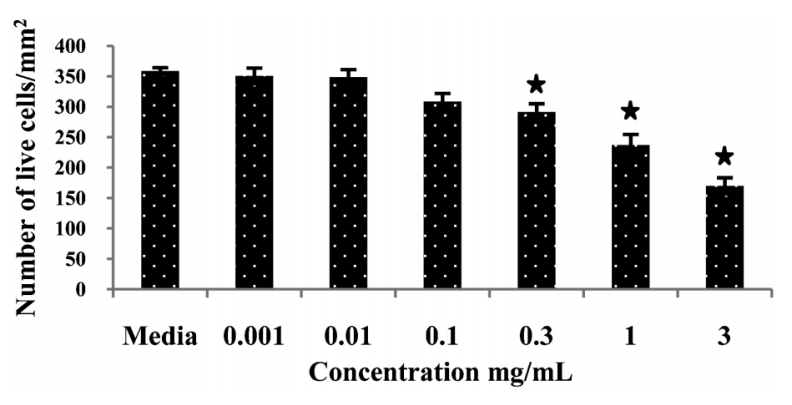

Fig. 3 Cytotoxic effect of a compound Ramizol ${ }^{\mathrm{TM}}$ on PC12 cells (Live/Dead Assay).§

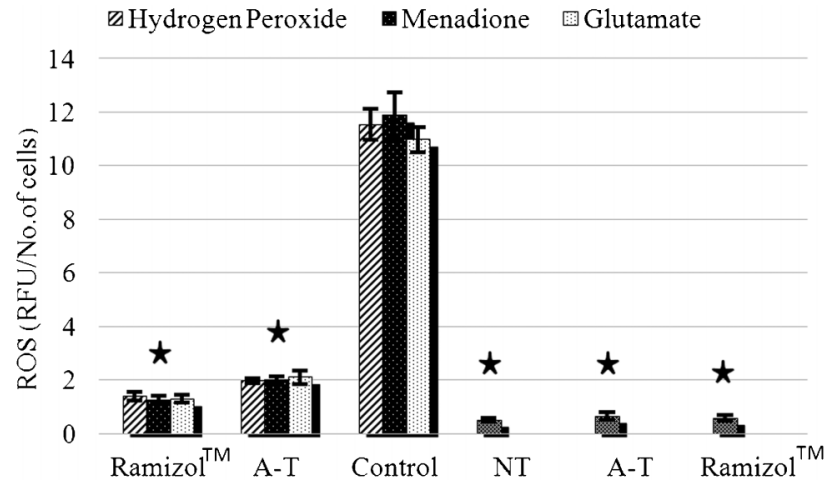

Fig. 4 Effect of Ramizol ${ }^{\mathrm{TM}}$ on intracellular ROS generation in PC12 cells.§ Ramizol ${ }^{\mathrm{TM}}$ (3 columns): stressed PC-12 cells treated with Ramizol ${ }^{\top \mathrm{M}}$ at $0.1 \mathrm{mg} \mathrm{mL} \mathrm{m}^{-1}$ concentration, A-T (3 columns): stressed PC-12 cells treated with $\alpha$-tocopherol at $0.01 \mathrm{mg} \mathrm{mL}^{-1}$ concentration, Control: control group treated with 3 different stressors without treatment with Ramizol ${ }^{\mathrm{TM}}$, NT (no treatment): PC-12 cells without oxidants and antioxidants treatment, A-T (1 column): PC-12 cells treated with $\alpha$-tocopherol and Ramizol ${ }^{\mathrm{TM}}$ (1 column): PC-12 cells treated with Ramizol ${ }^{\mathrm{TM}}$.

production and with $\alpha$-tocopherol a three-fold increase, which was significantly different from the no treatment and control groups. There was no significant increase in the ROS generation observed in the groups treated only with Ramizol ${ }^{\mathrm{TM}}$ and $\alpha$-tocopherol, and they were significantly different $(p \leqslant 0.05)$ from the control group. The cells pre-treated with Ramizol ${ }^{\mathrm{TM}}$ showed a similar trend to the $\alpha$-tocopherol treated group.

Effect of Ramizol ${ }^{\mathrm{TM}}$ on $\mathrm{H}_{2} \mathrm{O}_{2}$ induced increase in superoxide production in adult mouse and guinea pig cardiac myocytes

In cardiac tissue, persistent increases in ROS are associated with pathological remodeling and myocardial dysfunction. ${ }^{15-17}$ There is good evidence that increased ROS production following exposure of cardiac myocytes to sub-lethal levels of ROS contributes to the development of cardiac hypertrophy. ${ }^{18-21}$ We examined the effect of the compound Ramizol ${ }^{\mathrm{TM}}$ on $\mathrm{H}_{2} \mathrm{O}_{2}$ induced increase in superoxide production in individual adult mouse and guinea pig cardiac myocytes. Consistent with previous findings, transient exposure of mouse and guinea pig cardiac myocytes to a sub-lethal dose of $\mathrm{H}_{2} \mathrm{O}_{2}\left(30 \mu \mathrm{mol} \mathrm{L}{ }^{-1}\right)$ resulted in a significant increase in superoxide production ( $n=4, p<0.05$ ), Fig. 5. ${ }^{14}$ Exposure of cardiac myocytes to 2,10 or $20 \mu \mathrm{g} \mathrm{mL}^{-1} \mathrm{Ramizol}^{\mathrm{TM}}$ did not significantly alter this response. However, exposure of cardiac myocytes to 30 or $50 \mu \mathrm{g} \mathrm{mL}{ }^{-1} \mathrm{Ramizol}^{\mathrm{TM}}$ completely abolished the increase in superoxide production in response to $\mathrm{H}_{2} \mathrm{O}_{2}$ exposure $(n$ $=4$ and $n=5$ respectively, $p<0.05$ ).

\section{Discussion}

Antioxidants are free-radical scavengers which can provide protection to living organisms from damage caused by uncontrolled production of reactive oxygen species. ${ }^{22}$ The synthetic antioxidants used most commonly today are butylated hydroxyanisole (BHA), butylated hydroxytoluene (BHT), propylgallate (PG) and butylated hydroquinone..$^{23,24}$ 


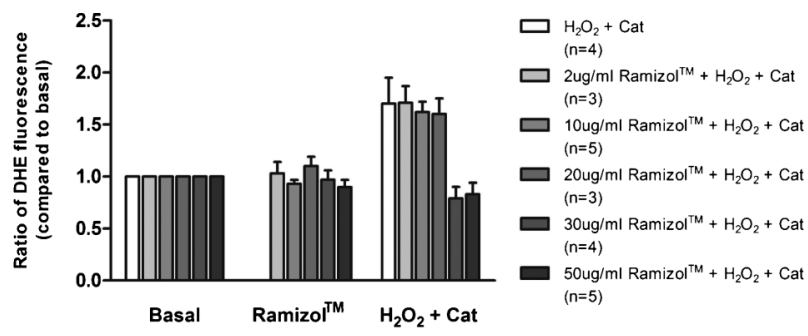

Fig. 5 Concentration-dependent effect of Ramizol $^{\mathrm{TM}}$ on hydrogen peroxideinduced increase in superoxide generation in cardiac myocytes $\S(n=$ number of cardiac myocytes).

ROS evaluation is used as an index to quantify the overall oxidative stress in cells. ${ }^{25}$ The elevated ROS generation was observed when the cells were treated with 3 stressors independent of its mechanism of oxidation. But the intracellular ROS generation, Fig. 2, was reduced considerably when the cells were treated with Ramizol ${ }^{\mathrm{TM}}$, which was concordant with previous reports of effective ROS inhibition by hydroxytyrosol (HTy) and hydroxytyrosol acetate (HTy-A). ${ }^{26}$

In cardiac tissue, persistent increases in ROS are associated with pathological remodeling and myocardial dysfunction. ${ }^{15-17}$ Increases in ROS beyond $100 \mu^{m o l ~ ~^{-1}}$ (extracellular) are associated with mitochondrial damage and damage to key macromolecules such as DNA, proteins and lipids. ${ }^{15,27-29}$ This ultimately leads to myocyte loss and heart failure. Sub-lethal increases in ROS (1-100 $\mu \mathrm{mol} \mathrm{l^{-1 }}$ extracellular) can result in the activation of a number of calcium-dependent signalling pathways that have been associated with pathological growth and progression towards cardiac hypertrophy in the absence of cell death. ${ }^{15,18-21,27,30,31}$ In myocytes, this is associated with increased protein synthesis in the absence of apoptosis or necrosis, ${ }^{18-21}$ and a small but significant increase in cell area 48 $\mathrm{h}$ following the initial exposure to $\mathrm{H}_{2} \mathrm{O}_{2} \cdot{ }^{21}$

We tested the effect of Ramizol ${ }^{\mathrm{TM}}$ on ventricular myocytes isolated from mouse and guinea-pig hearts to determine whether the compound was effective after an oxidative stress challenge in native cells. Consistent with previous findings, we find that transient exposure to $30 \mu \mathrm{mol} \mathrm{L}{ }^{-1} \mathrm{H}_{2} \mathrm{O}_{2}$ results in a significant increase in superoxide production in mouse and guinea pig cardiac myocytes. ${ }^{14}$ Exposure to concentrations of Ramizol ${ }^{\mathrm{TM}}$ within the range of $30-50 \mu \mathrm{g} \mathrm{mL} \mathrm{m}^{-1}$ completely attenuated the increase in superoxide production in response to transient exposure of mouse and guinea pig cardiac myocytes to $30 \mu \mathrm{mol}$ $\mathrm{L}^{-1} \mathrm{H}_{2} \mathrm{O}_{2}$.

The electrochemistry of Ramizol ${ }^{\mathrm{TM}}$ was studied at a buffered $\mathrm{pH}$ of 7 using phosphate with $\mathrm{KNO}_{3}$ as the electrolyte. No redox peaks were observed between $-0.4 \mathrm{~V}$ and $0.7 \mathrm{~V}$ vs. $3.5 \mathrm{M} \mathrm{KCl} \mathrm{Ag-}$ $\mathrm{AgCl}$ (Fig. S1, ESI†). This range was extended to between $-1.2 \mathrm{~V}$ and $0.7 \mathrm{~V}$ vs. $3.5 \mathrm{M} \mathrm{KCl} \mathrm{Ag}-\mathrm{AgCl}$ using a $\mathrm{pH}$ of 12 at $0.1 \mathrm{M}$ phosphate solution with no observable peaks that could not be excluded from the electrodes' background. This potential range includes the electrochemical behaviour of the majority of biological redox active compounds such as vitamin B, C and $\mathrm{E}^{32,33}$ The lack of redox peaks indicates that the antioxidant behaviour of Ramizol ${ }^{\mathrm{TM}}$ either follows an auto-oxidation type mechanism, as has been observed in unsaturated fats, or a secondary role, such as that observed in saturated fats. ${ }^{34,35}$ Given the presence of carboxylic acid moieties and unsaturation in Ramizol $^{\mathrm{TM}}$, auto-oxidation is a more plausible mechanism for the antioxidant behaviour of the drug but this is yet to be confirmed and will be a topic in future work.

We have shown that the novel and non-toxic antimicrobial, Ramizol $^{\mathrm{TM}}$, is also a potent antioxidant. These findings make the drug an attractive candidate for fighting infections in patients with an on-going oxidative stress disorder or a compromised immune system.

\section{Conclusion}

Our study suggests that Ramizol ${ }^{\mathrm{TM}}$ is a potent synthetic compound that exhibits effective inhibition of ROS generation compared to $\alpha$-tocopherol, which is a standard antioxidant drug. The results show that Ramizol ${ }^{\mathrm{TM}}$ decreases ROS to basal levels in PC12 cells and mouse and guinea pig myocytes, and demonstrate its protective nature from oxidative damage to the cells. The continual challenge to discover antibiotics with no or few side effects makes Ramizol ${ }^{\mathrm{TM}}$ a very attractive candidate for the potential treatment of infections.

\section{Acknowledgements}

The effect of Ramizol ${ }^{\mathrm{TM}}$ on adult mouse and guinea pig cardiac myocytes study was supported by grants from the National Health and Medical Research Council of Australia and Australian Research Council. Livia Hool is an Australian Research Council Future Fellow and Honorary National Health and Medical Research Council Senior Research Fellow. Helena Viola is a recipient of a National Heart Foundation of Australia Postdoctoral Fellowship.

\section{Notes and references}

\$ The authors would kindly like to thank Dr Adrian Scaffidi for the synthesis of Ramizol ${ }^{\mathrm{TM}}$.

$\S$ Values are expressed as mean \pm SEM of three determinations.

* indicates significant difference $(p<0.05)$ from the control group.

1 H. Sies, Exp. Physiol., 1997, 82, 291-295.

2 E. Esposito, D. Ratilio, V. Di Matteo, C. Di Glulia, M. Cacchio and S. Algeri, Neurobiol. Aging, 2002, 23, 719-735.

3 C. Behl, Prog. Neurobiol., 1999, 57, 301-323.

4 T. Finkel, Nature, 2000, 408, 239-248.

5 K. J. A. Davies, IUBMB Life, 2000, 50.

6 K. Nose, Biol. Pharm. Bull., 2000, 23, 897-903.

7 A. M. Papas, Lipids, 1996, 31, 77-82.

8 M. C. Polidori, W. Stahl, O. Eichler, I. Niestroj and H. Sies, Free Radical Biol. Med., 2001, 30, 456-462.

9 US Patent Appl., No. 13/517,455.

10 R. A. Boulos, PhD Thesis, Chemistry, University of Western Australia, Crawley, 2011.

11 N. A. Lengkeek, R. A. Boulos, A. J. McKinley, T. V. Riley, B. Martinac and S. G. Stewart, Aust. J. Chem., 2011, 64, 316-323.

12 L. A. Greene and A. S. Tischler, Proc. Natl. Acad. Sci. U. S. A., 1976, 73, 2424-2428. 
13 L. C. Hool, Circ. Res., 2000, 87, 1164-1171.

14 H. M. Viola, et al., Circ. Res., 2007, 100, 1036-1044.

15 A. Sabri, H. H. Hughie and P. A. Lucchesi, Antioxid. Redox Signaling, 2003, 5, 731-740.

16 R. Bolli, Basic Res. Cardiol., 1998, 93, 156-162.

17 D. J. Grieve, et al., Heart, Lung Circ., 2004, 13, 132-138.

18 S. H. Kwon, J. Mol. Cell. Cardiol., 2003, 35, 615-621.

19 Q. M. Chen, et al., Arch. Biochem. Biophys., 2000, 373, 242-248.

20 V. C. Tu, et al., J. Pharmacol. Exp. Ther., 2002, 300, 1101-1110.

21 V. Seenarain, et al., J. Proteome Res., 2010, 9, 1985-1994.

22 S. Ghosal, V. K. Tripathi and S. Chaeruhann, Indian J. Chem., 1996, 35, 941-948.

23 H. P. Wichi, Food Chem. Toxicol., 1988, 26, 723-727.

24 E. R. Sherwin, A. L. Brancn, P. M. Davidson and S. Salmincn, Food Additives, Marvel Dekker Inc, New York, 1990.

25 B. Queguineur, L. Goya and S. Ramos, et al., Food Chem. Toxicol., 2012, 50, 2886-2893.
26 G. Pereira-Caro, B. Sarria and A. Madrona, et al., J. Agric. Food Chem., 2011, 59, 5964-5976.

27 J. R. Stone and S. Yang, Antioxid. Redox Signaling, 2006, 8, 243-270.

28 D. B. Sawyer, et al., J. Mol. Cell. Cardiol., 2002, 34, 379-388.

29 F. J. Giordano, J. Clin. Invest., 2005, 115, 500-508.

30 N. Frey and E. N. Olsen, Annu. Rev. Physiol., 2003, 65, 45-79.

31 V. P. van Empel and L. J. De Windt, Cardiovasc. Res., 2004, 63, 487-499.

32 W. W. Yao, H. M. Peng and R. D. Webster, J. Phys. Chem. C, 2009, 113, 21805-21814.

33 H. Y. Gu, A. M. Yu and H. Y. Chen, Anal. Lett., 2001, 34, 2361-2374.

34 I. P. Freeman, in Ulmann's Encyclopedia of Industrial Chemistry, Wiley-VCH Verleg GmbH \& Co. KGaA, Weinheim, 2000.

35 G. E. Henry, R. A. Momin, M. G. Nair and D. L. Dewitt, J. Agric. Food Chem., 2002, 50, 2231-2234. 